\title{
Recruitment of Long-lasting and Protein Kinase A-dependent Long-term Potentiation in the CA1 Region of Hippocampus Requires Repeated Tetanization
}

\author{
Yan-You Huang and Eric R. Kandel \\ Center for Neurobiology and Behavior \\ College of Physicians and Surgeons of Columbia University and Howard Hughes Medical Institute \\ New York, New York 10032
}

\section{Abstract}

To study how the late phase of long-term potentiation (LTP) in hippocampus arises, we examined the resulting LTP for its time course and its dependence on protein synthesis and different second-messenger kinases by applying various conditioning tetani. We find that one high-frequency train $(100 \mathrm{~Hz})$ produces a form of LTP that lasts longer than $1 \mathrm{hr}$ but less than $3 \mathrm{hr}$ (the early phase of LTP, or E-LTP). It is blocked by inhibitors of calcium/calmodulin kinase II (Cam kinase II) but is not affected by an inhibitor of cAMP-dependent protein kinase [protein kinase A (PKA) and the protein synthesis inhibitor anisomycin] nor is it occluded by the cAMP activator forskolin. In contrast, when three high-frequency trains are used, the resulting potentiation persists for at least 6-10 hr. The L-LTP induced by three trains differs from the E-LTP in that it requires new protein synthesis, is blocked by an inhibitor of cAMP-dependent protein kinase, and is occluded by forskolin. These results indicate that the two mechanistically distinctive forms of LTP, a transient, early component (E-LTP) and a more enduring form (L-LTP), can be recruited selectively by changing the number of conditioning tetanic trains. Repeated tetani induce a PKA and protein synthesis-dependent late component that adds to the amplitude and duration of the potentiation induced by a single tetanus.

\section{Introduction}

Long-term potentiation (LTP) in the intact animal lasts days to weeks (Bliss and Collingridge, 1993). This persistent feature has made it an attractive candidate mechanism for certain types of memory storage in the mammalian brain (Squire 1992). In earlier work (Frey et al. 1993), we began to explore this enduring component mechanistically by studying it in hippocampal slices. We found that repeated tetani applied to the Schaffer collaterals induce an enduring long-term potentiation in CA1 neurons that lasts for at least $10 \mathrm{hr}$ (Matthies 1989; Frey et al. 1993). Application of a cAMP analog simulated the late phase of LTP and an inhibitor of the CAMP-dependent protein kinase blocked this late phase, suggesting that CAMP may be required for the late phase of LTP (Frey et al. 1993; Matthies and Reymann 1993). How does this late phase emerge? Here, we examine this question using three approaches. First, we use different numbers and intensities of conditioning tetanic trains to see how different conditioning procedures determine the time course of the resulting LTP. Second, we examine the effects of inhibitors of protein synthesis on the LTP produced by different conditioning procedures. Finally, we explore the roles of $\mathrm{Ca}^{2+} /$ calmodulin kinase II (Cam kinase II) and cAMP-dependent protein kinase A (PKA) on the different components of LTP produced by the different conditioning procedures.

\section{Materials and Methods}

Transversely cut hippocampal slices $(400 \mu \mathrm{m})$ were prepared from 5- to 6-week-old Sprague-

LEARNING \& MEMORY 1:74-82 (c) 1994 by Cold Spring Harbor Laboratory Press ISSN1072-0502/94 \$5.00

$$
\begin{array}{llllllllllllllll}
\hline & E & A & R & N & I & N & G & \begin{array}{l}
\mathbf{X} \\
\mathbf{7 4}
\end{array} & M & E & M & O & R & Y
\end{array}
$$


Dawley rats. An interface chamber was used, with a flow rate of continuous superfusion at $1.5-2 \mathrm{ml}$ / min. The solution composition was (in $\mathrm{mM}$ ) $\mathrm{NaCl}$, 124; $\mathrm{MgSO}_{4}, 1.3 ; \mathrm{KCl}, 4.9 ; \mathrm{KH}_{2} \mathrm{PO}_{4}, 1.2 ; \mathrm{CaCl}, 2.5$; $\mathrm{NahCO}_{3}, 25.6$; and D-glucose, 10, bubbled with $95 \% \mathrm{O}_{2}$ and $5 \% \mathrm{CO}_{2}$. When picrotoxin (30-50 $\mu \mathrm{M})$ was added to the solution, both $\mathrm{CaCl}_{2}$ and $\mathrm{MgSO}_{4}$ were increased to $4 \mathrm{~mm}$. The temperature of the solution was maintained at $\sim 28^{\circ} \mathrm{C}$. Experiments were started after preincubation of the slices for $2 \mathrm{hr}$. Extracellular recordings were made from the stratum radiatum of the CA1 region, using stainless steel electrodes. To elicit synaptic responses, Schaffer collateral/commissural afferents in stratum radiatum were stimulated with insulated bipolar stainless steel electrodes.

The baseline was recorded for $30-60 \mathrm{~min}$ before drug application or LTP-inducing tetanization. Four biphasic constant current pulses $(0.2 \mathrm{~Hz}$, duration of $0.1 \mathrm{msec}$ ) were used for testing at $10-\mathrm{min}$ intervals in the first hour after LTP induction and at $30 \mathrm{~min}$ intervals in the following hours. In LTP experiments, an additional test was performed 1 min after tetanization. To induce LTP, three protocols of tetanization were used: (1) $100 \mathrm{~Hz}$ for 1 sec, one train with the duration of pulses during tetanization at $0.1 \mathrm{msec}$; (2) $100 \mathrm{~Hz}$ for $1 \mathrm{sec}$, one train with the duration of pulses during tetanization at $0.2 \mathrm{msec}$; (3) $100 \mathrm{~Hz}$ for $1 \mathrm{sec}$, three trains with tetanization at 10 -min intervals and the duration of the pulses during tetanization at $0.2 \mathrm{msec}$. The average waveform from four successive responses was saved and the slope of EPSP $(\mathrm{mV} /$ msec) was measured. All data were normalized to the last group of responses recorded prior to tetanus.

The following drugs were made and stored as concentrated stock solutions and were diluted 1000-fold when applied to the perfusion solution: $1 \mathrm{~mm} \mathrm{KT} 5720$ (Biomol, dissolved in DMSO); $1 \mathrm{~mm}$ KT5926 (Biomol, dissolved in DMSO); $50 \mathrm{~mm}$ forskolin (Sigma, dissolved in DMSO); $50 \mathrm{~mm} \mathrm{3} 3^{\prime}{ }^{\prime}$ isobutyl-1-methylaxanthine (IBMX) (Sigma, dissolved in DMSO); and $20 \mathrm{~mm}$ anisomycin (Sigma, dissolved in water).

\section{Results}

To study the emergence of the various components of LTP and the role of protein synthesis and the cAMP-dependent protein kinase in these components, we used three types of conditioning procedures and compared the effect on the resulting LTP of two types of inhibitors: (1) inhibitors of protein synthesis, and (2) inhibitors of secondmessenger protein kinases.

We first used a single train of $100 \mathrm{~Hz}$ for $1 \mathrm{sec}$ (type 1 tetanization protocol). Here, the duration of the pulse during tetanization was $0.1 \mathrm{msec}$, which was the same duration as that used for test stimuli. Type 1 tetanization induced modest LTP. The peak increase in amplitude of the excitatory postsynaptic potential (EPSP) (measured as an increase in slope), evident at $10 \mathrm{~min}$, was $141 \pm 9 \%$ (mean \pm S.E.M.; $n=6$ ). At $1 \mathrm{hr}$ the increase in slope of the EPSP was $121 \pm 6 \%$. This LTP did not persist and declined to $112 \pm 8 \%$ by $3 \mathrm{hr}$ after tetanization $(n=6)$. The modest LTP produced by type 1 tetanization does not require new protein synthesis. The protein synthesis inhibitor anisomycin (20 $\mu \mathrm{M}$ ) had no effect on this component of LTP (Fig. 1C). Nor does this component of LTP require the recruitment of the cAMP-dependent protein kinase. The PKA inhibitor KT5720 (1 $\mu \mathrm{M})$, which acts on the catalytic subunit (Cabell and Audesirk 1993), had no effect on this phase of LTP (Fig. 1B). This is consistent with our earlier finding that a single tetanus does not cause an increase in the level of cAMP (Frey et al. 1993). This early, transient component of LTP does, however, require the activation of other second-messenger kinases (see also Malinow et al. 1989). It is reduced by KT5960 (1 $\mu \mathrm{M})$ (Fig. 1A), an inhibitor of serine threonine kinases that, at this concentration, has potent effects on Cam kinase II but little effect on PKA (Hashimoto et al. 1991). In the presence of KT5960 only short-term potentiation (STP) remains (see also Malenka 1991).

These results indicate that the potentiation induced by the type 1 tetanization protocol has all the features of early-phase LTP (E-LTP) studied by others (see Malinow et al. 1989). It is different from STP, both in its requirement for Cam kinase II and its persistence for $>1 \mathrm{hr}$. It differs from late-phase LTP (L-LTP) in not requiring new protein synthesis.

We then used a single train of $100 \mathrm{~Hz}$ for 1 sec but have now increased the duration of each stimulus during the tetanization from 0.1 to 0.2 msec (type 2 tetanization protocol). This is double the duration of the test stimuli. This stronger tetanus produced a slightly larger and more persistent LTP than did type 1 tetanization protocol. The peak increase in the amplitude of the EPSP (again measured at $10 \mathrm{~min})$ was $165 \pm 4 \%(n=7)$, rather

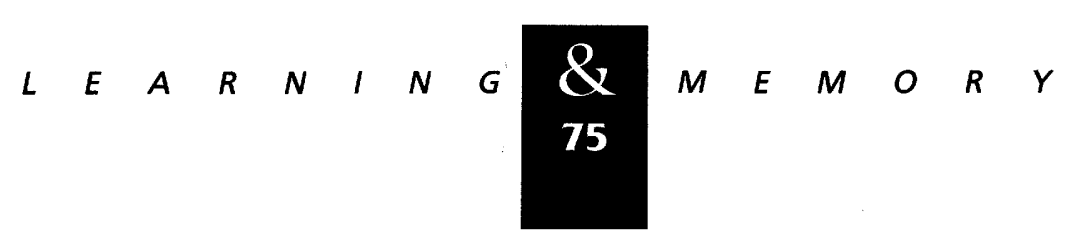




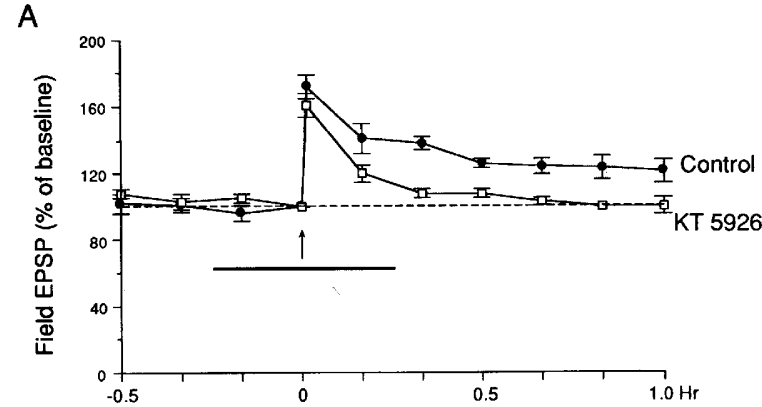

B

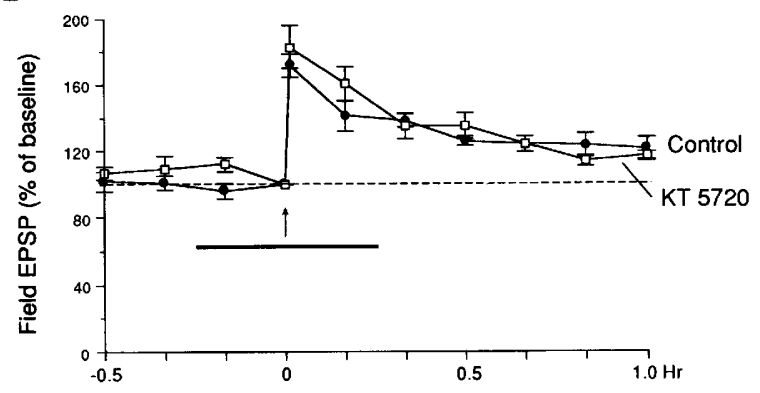

C

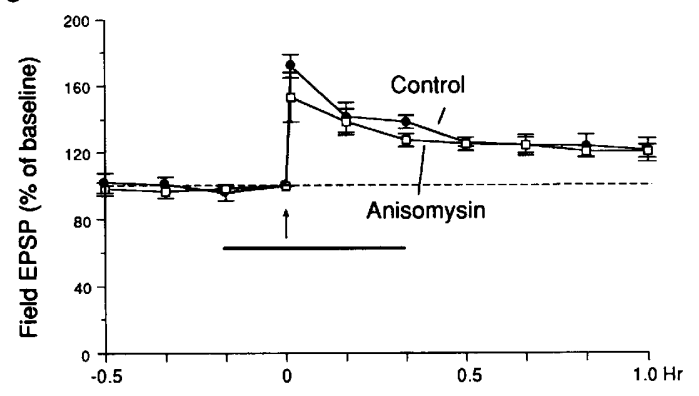

Figure 1: A comparison of kinase inhibitors and a protein synthesis inhibitor on LTP induced by one tetanization train at a moderate intensity. (A) KT5926 (1 $\mu \mathrm{M})$, a $\mathrm{Ca}^{2+} /$ calmodulin kinase inhibitor (indicated by the bar), depressed the LTP induced by one train at a moderate intensity $(100 \mathrm{~Hz}, 0.1 \mathrm{msec}, 1 \mathrm{sec}$, indicated by the arrow, $n=5)$. (B) KT5720 (1 $\mu \mathrm{M})$, a PKA inhibitor (indicated by the bar), had no effect on LTP induced by one train at a moderate intensity $(n=5)$. (C) The protein synthesis inhibitor anisomycin $(20 \mu \mathrm{M})$ also had no effect on LTP produced by one train at this intensity LTP $(n=6)$.

than $141 \%$ (with type 1 tetanization). At $1 \mathrm{hr}$ the slope was still $145 \pm 9 \%(n=7)$. The Cam kinase II inhibitor KT5926 ( $1 \mu \mathrm{M})$ again depressed this form of LTP as it did the weaker form (Fig. 2A). KT5926 also has some effect on post-tetanic potentiation (PTP) in this type of tetanization, which is similar to that of the Cam kinase II antagonist CBP (Malenka et al. 1989). The PKA inhibitor KT5720 (1 $\mu \mathrm{M})$ again had no effect on the early phase of LTP evident during the first $40 \mathrm{~min}$ (Fig.
2B). However, it slightly reduced a later phase of LTP evident at $50 \mathrm{~min}$ and at $90 \mathrm{~min}$ after tetanization. But this reduction was not significant at either of these time points ( $P>0.5$, Student's $t$-test). Similarly, the protein synthesis inhibitor anisomycin had no effect on the early phase of LTP (two animals). These results suggest that this early phase, recruited by a single train of either weak or strong intensity, does not require the participation of PKA or protein synthesis.

Finally, we used three trains of stimuli at $\mathbf{1 0 0}$ $\mathrm{Hz}$ for $1 \mathrm{sec}$ at 10 -min intervals, with the duration of each stimulus during tetanus being $0.2 \mathrm{msec}$, double the test stimuli (type 3 conditioning protocol). This type of conditioning protocol, which
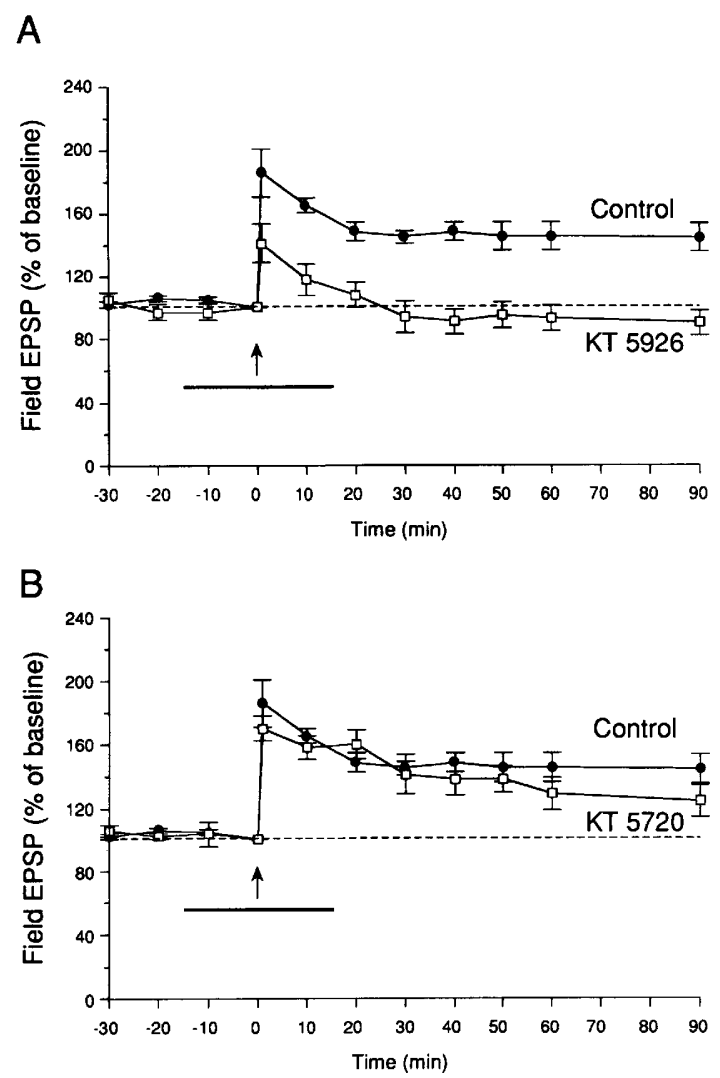

Figure 2: A comparison of the actions of inhibitors of $\mathrm{Ca}^{2+} /$ calmodulin kinase and of PKA on LTP produced by one tetanization train but with a longer duration pulse $(0.2 \mathrm{msec}$ rather than $0.1 \mathrm{msec}$ as in Fig. 1 , at 100 $\mathrm{Hz}$ for $1 \mathrm{sec})$. This produced a stronger induction of LTP than in Fig. 1. (A) KT5926 (1 $\mu \mathrm{M}, n=5)$, a Ca ${ }^{2+} / \mathrm{cal}-$ modulin inhibitor (indicated by the bar), depressed the LTP induced by one tetanization train $(100 \mathrm{~Hz}, 0.2$ msec, $1 \mathrm{sec})$. (B) KT5720 (1 $\mu \mathrm{M}, n=6)$, an inhibitor of PKA, had no significant effect on LTP induced by one train at a stronger intensity $(100 \mathrm{~Hz}, 0.2 \mathrm{msec}, 1 \mathrm{sec})$.

$$
\ldots \ldots, \int_{10}^{8} \ldots \ldots
$$




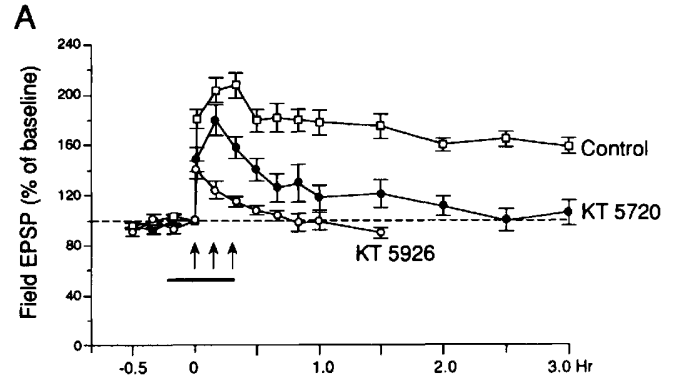

B
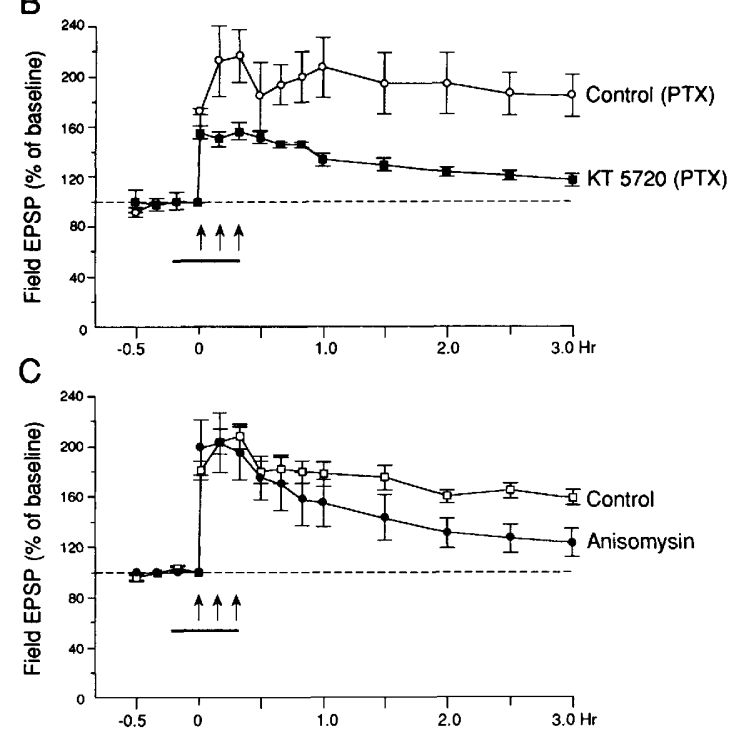

Figure 3: A comparison of kinase and protein synthesis inhibitors on LTP induced by three trains of tetanization $(100 \mathrm{~Hz}$ for $0.2 \mathrm{msec}, 1 \mathrm{sec})$. (A) KT5720 (1 $\mu \mathrm{M})$ caused a slow decay of LTP induced by three trains of tetanus (arrows, $n=6)$, whereas KT5926 (1 $\mu \mathrm{M})$ caused a faster decay $(n=5)$. (B) KT5720 $(1 \mu \mathrm{M})$ caused a slow decay of LTP induced by three trains of tetanus in the presence of picrotoxin (solid line, $n=5)$. (C) Anisomycin (20 $\mu \mathrm{M}$ ) caused a slow decay of LTP induced by three trains of tetanization.

we used in our earlier studies (Frey et al. 1993), produced a robust and enduring form of LTP. Not only was the early phase of LTP large, but, in addition, a prominent and enduring late phase appeared. The peak slope increase at $10 \mathrm{~min}$ after the third tetanus was now $180 \pm 9 \%(n=11)$, and this increase persisted unchanged at $1 \mathrm{hr}(178 \pm 10 \%$, $n=11$ ). It was only slightly reduced at $3 \mathrm{hr}$ posttetanization $(156 \pm 6 \%, n=11)$. In earlier experiments (Frey et al. 1993), we found that this phase, as produced by this protocol, persists for at least 8-10 hr.

All of these added components were blocked by KT5720, an inhibitor of PKA (Fig. 3A). Thus, the inhibitor of PKA reduced slightly an early phase of LTP that begins $10 \mathrm{~min}$ after the last (the third) train of tetanization. This PKA-dependent component grows larger with time. Sixty minutes after tetanization the inhibitor of PKA reduced the LTP from $178 \pm 10 \%, n=11 ; P<0.01)$ to $118 \pm 10 \%(n=5)$. At $3 \mathrm{hr}$ after tetanization LTP was almost completely blocked. It was reduced from $156 \pm 6 \%, n=11$, to $106 \pm 10 \%, n=5$, $P<0.01$. The depressive effect of the PKA inhibitor on LTP seen in this type of tetanization during the first hour is probably not attributable to nonspecific effects. Because the same dosage of the inhibitor had no effect on LTP during the first hour of type 1 and type 2 tetanization, it also had no effect on LTP when applied after the tetanization (see Fig. 4). These results are similar to those obtained by Frey et al. (1993) with Rp-cAMP, a different inhibitor of PKA, and to the those of Matthies and Reymann (1993) with lower dosages of KT5720 in different experimental conditions (higher temperatures). On the other hand, the inhibitor of Cam kinase II (KT5926, $1 \mu \mathrm{M}$ ) completely blocked the LTP within 10-20 min after three trains of tetanus (Fig. 3A), which is much faster than the effect of inhibitor of PKA.

The late phase, which emerged with three tetanus trains, requires new protein synthesis. In the presence of anisomycin, LTP started to decay at $\sim 30-40 \mathrm{~min}$ after the tetani (Fig. 3C). At $3 \mathrm{hr}$ after tetanization, LTP was $123 \pm 11(n=6)$, which was

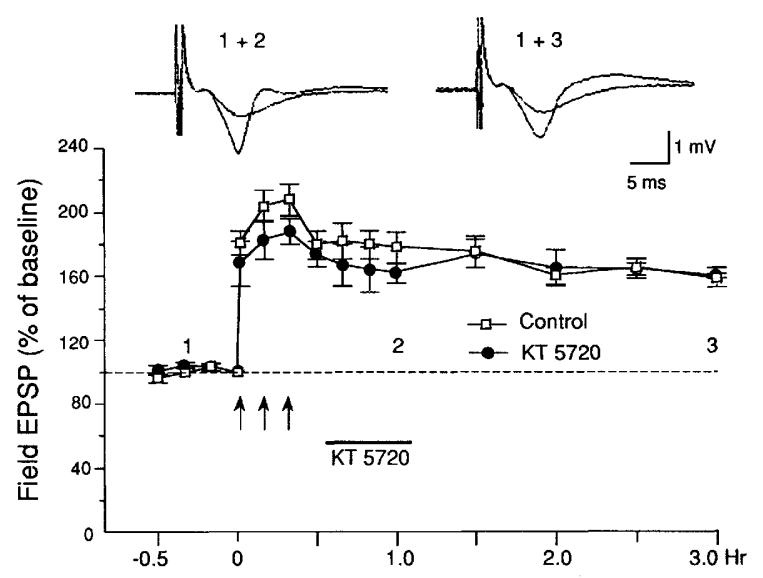

Figure 4: The effects of the PKA inhibitor applied after three trains of tetanization. KT5720 (1 $\mu \mathrm{M})$ applied 15 min after the third tetanus caused no significant change of LTP $(n=5)$. Representative averages of four consecutive field EPSPs $10 \mathrm{~min}$ before tetanus (1), $60 \mathrm{~min}$ after tetanus (2), and $180 \mathrm{~min}$ after tetanus (3) are shown at the top.

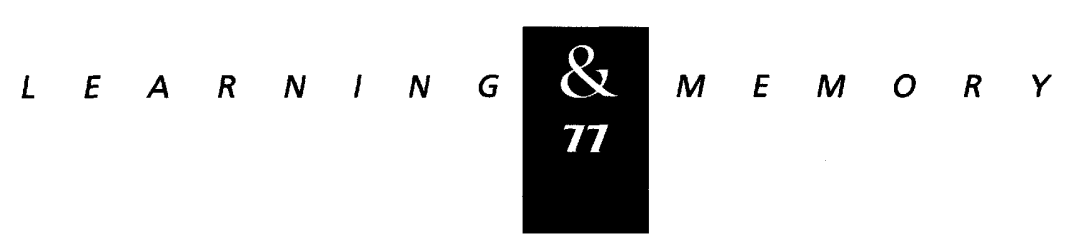


significantly different from LTP in drug-free solution $(P<0.05)$. This time course is similar to that obtained for the effects of protein synthesis inhibition on LTP in other laboratories (Otani et al. 1992). The effects of anisomycin were thus similar (but not identical) to inhibitors of PKA. In addition to producing a slow decay of LTP similar to that produced by anisomycin, the PKA inhibitor also caused a reduction in E-LTP, suggesting that besides its effect on a later protein synthesis-dependent component, PKA mediates an early component of LTP (produced by repeated tetani) that does not require new protein synthesis. Thus, three tetani induce a new and cAMP-dependent component that begins within minutes of the last tetanus and lasts for at least 8-10 hr (Frey et al. 1993).

The cAMP-dependent step begins quite early, within $10 \mathrm{~min}$ after the third train of the tetanic conditioning procedure and recruits a protein synthesis-dependent component that persist for many hours. What is the mechanism for this cAMP-dependent component? Does it require continued activity of PKA? Earlier work had indicated that this cAMP-dependent component is not the result of a persistent increase in cAMP. Thus, the increase in CAMP produced by three training trials is transient and returns to baseline levels within minutes after the last tetanus (Chetkovich et al. 1991; Frey et al. 1993). Is the persistence of LTP attributable to the fact that the transient elevation in cAMP triggers continued activity of PKA? To test this idea we applied the PKA inhibitor 15 min after the last tetanization. Under these conditions we observed no change in LTP (Fig. 4). This suggests that the maintenance of L-LTP does not require persistent activation of PKA. Rather, PKA must trigger some subsequent, perhaps protein synthesis-dependent step, which maintains the potentiation.

How does cAMP produce its effect? Does it act primarily on the direct connections between the Schaffer collaterals of the CA3 pyramidal cells and the CA1 neurons? Or does it modulate the GABA receptor and alter the inhibitory pathway, which has a profound effect on synaptic excitability (Stephen et al. 1992)? To examine whether PKA exerts its effect through the GABA-ergic inhibitory pathway, we blocked the pathway using picrotoxin. Even in the presence of picrotoxin, KT5720 depressed the LTP induced by type 3 tetanization. No significant difference was observed between the effects obtained in slices treated or not treated with picrotoxin, although the depression became slightly weaker in the presence of picrotoxin (Fig. 3B).

If the PKA cascade becomes recruited with three tetanic trains, the LTP produced by one tetanus (which does not recruit PKA) would not be expected to be occluded by cAMP agonists, whereas the later phase, induced by three tetani, should be occluded. We have previously reported that $\mathrm{Sp}-\mathrm{cAMP}$-induced potentiation could occlude L-LTP induced by three tetanic trains of stimuli (Frey et al. 1993). We reexamined the occlusive effects of cAMP agonists on one-train as compared with three-train LTP using another protocol. Bath application of the adenylyl cyclase activator forskolin $(50 \mu \mathrm{M})$ in the presence of $50 \mu \mathrm{M}$ of the phosphodiesterase inhibitor IBMX (which prevents the destruction of cAMP) induces a synaptic potentiation that resulted from an increase in endogenous CAMP. This potentiation is blocked by inhibitors of adenylyl cyclase (see Chavez-Noriega and Stevens 1992). The synaptic potentiation produced by forskolin/IBMX did not occlude the E-LTP induced by one train using the type 2 protocol (Fig. 5A1). However, the late component of LTP, which had its onset at $\sim 20 \mathrm{~min}$, was occluded by forskolin after the last of three trains of tetanization. This occlusion became significant 70 min after the last tetanization $(130 \pm 10 \%, n=5$, compared with $165 \pm 6 \%, n=11, P<0.05$ ) (Fig. 5B1), which is similar to the occlusion results of Sp-cAMP reported previously (Frey et al. 1993). The differential occlusion evident with the cAMP agonist on LTP produced with three as compared with one train is consistent with the effects seen with the inhibitor of PKA. The slightly delayed depression of LTP in the occlusion experiments, as compared with the results of the inhibitor (Fig. 3), could be attributable to the effects of IBMX, which increases transmitter release and may compensate for some portion of the depression induced by occlusion.

These results, based on the use of different inhibitors and stimulators of the cAMP pathway, confirm the previous finding that the cAMP-dependent protein kinase contributes to the late phase of LTP (Frey et al. 1993). In addition, the data suggest that PKA becomes recruited during E-LTP (0$90 \mathrm{~min}$ ) in a tetanization-dependent manner. In Figure 6, the effects of the PKA inhibitor on E-LTP under the three types of conditioning tetanization are plotted on the same time scale. The component of LTP induced by three tetanization trains

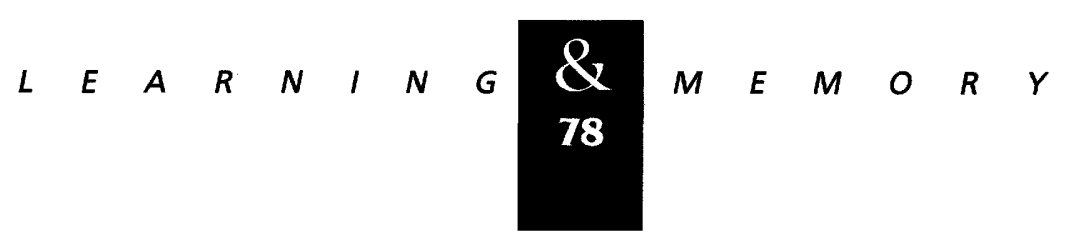


A1

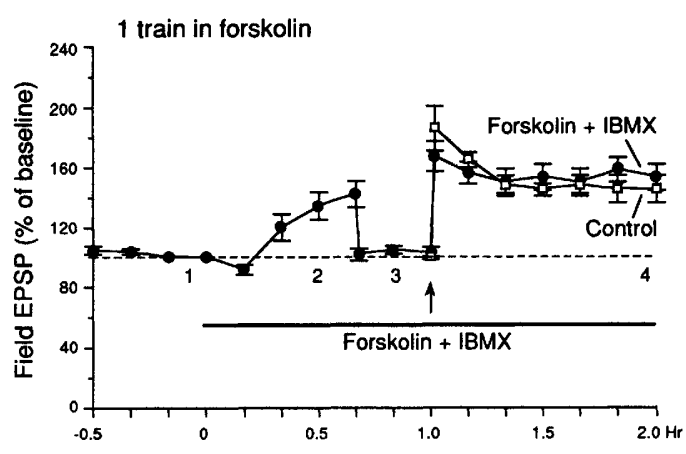

B1

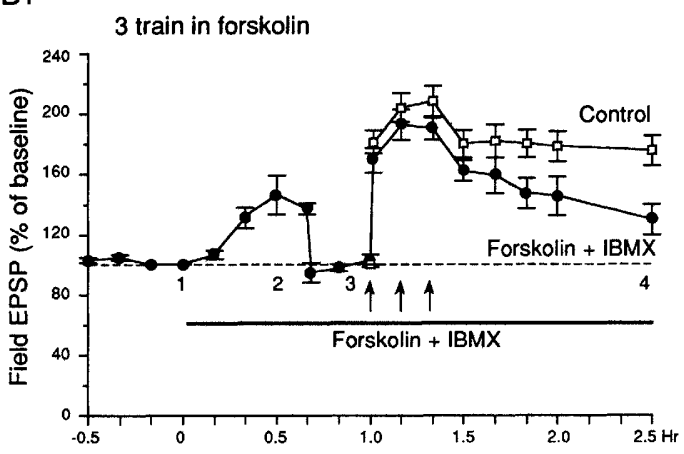

$\mathrm{A} 2$
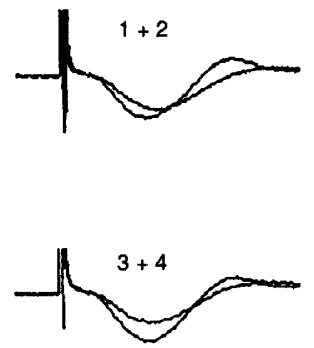

$\mathrm{B} 2$

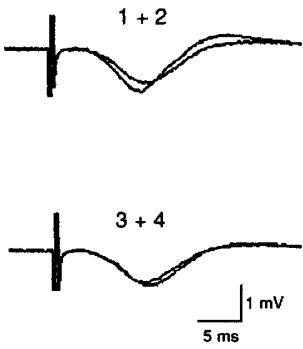

Figure 5: The occlusive effects of forskolin-induced potentiation on LTP induced by tetanization. (A) Potentiation was induced by forskolin plus IBMX (50 $\mu \mathrm{M}$ each, indicated by the bar). Forty minutes later, the stimulus intensity was reduced to baseline level and one tetanization train $(100 \mathrm{~Hz}, 0.2 \mathrm{msec}, 1 \mathrm{sec})$ was given. This now produced a substantial E-LTP, which was not different from the LTP obtained in control experiments in a drugfree solution ( $\square, n=7$ ). A2 shows representative recordings of four consecutive field EPSPs averaged at the different time points illustrated in $A 1$. (B) Synaptic potentiation was again induced by application of forskolin plus IBMX. Forty minutes later, the stimulus intensity was reduced and three tetanization trains were given $(n=5)$. Now there was a slow decay of the LTP induced by three tetanization trains, indicating that forskolin plus IBMX occludes the late but not the early phase. ( $\square$ ) LTP in a drug-free solution $(n=11)$. $B 2$ shows the representative changes in field EPSPS at the different time points illustrated in $B 1$.

(type 3) and that which remains following inhibition of PKA is similar to the residual component after one-train (type 2) tetanization. In turn, this component is also similar to the LTP induced by one-train (type 2) tetanization in drug-free solu-

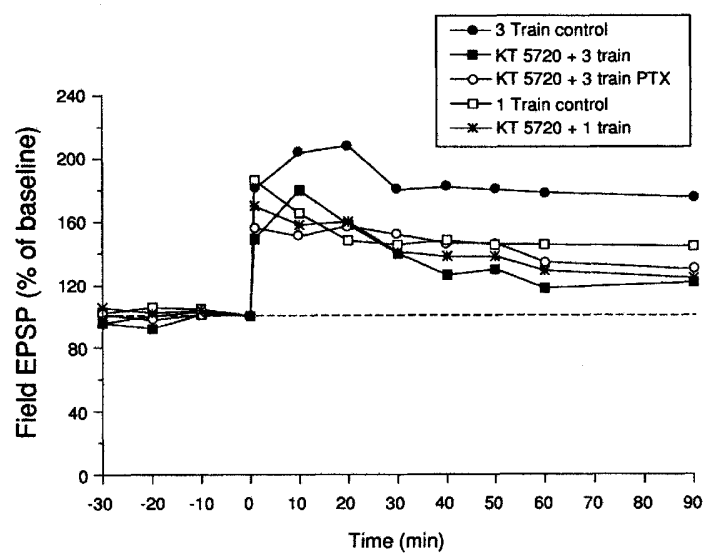

Figure 6: Overlapping of LTP induced by one train and three tetanic trains in the presence of a PKA inhibitor. KT5720 $(1 \mu \mathrm{M})$ caused only a slight change of LTP induced by one train (100 Hz for $0.2 \mathrm{msec}, 1 \mathrm{sec}$ ), whereas the LTP induced by three trains was reduced to the level of LTP induced by one train. tion during the first hour. These data indicate that inhibiting PKA reduces the LTP induced by three trains to the level of LTP produced by one train and suggests that the additional early and late components of LTP induced by three trains are mediated by CAMP and PKA acting either independently or, more likely, synergistically, with the protein kinases recruited for the early phase.

\section{Discussion}

LTP is an attractive candidate mechanism for long-term information storage because it can readily be extended to last for many hours and even days (Squire 1992; Bliss and Collingridge 1993). Whereas much is now known about the biochemical steps involved in the initiation of LTP (Malenka and Nicoll 1990; Bliss and Collingridge 1993), little is known about its extension into a persistent phase that lasts for days. Previously, we found that this late phase requires CAMP and new protein synthesis (Frey et al. 1993). By using different tetanization protocols, we have been able to selectively study an early phase that does not require protein synthesis or CAMP and to describe 
how the late phase emerges from this early phase with repeated tetanization. Our data reveal that the three tetanic trains needed to induce the late phase also induce an additional component of the early phase. This addition to the early phase also is dependent on PKA.

These studies and those of others (Malinow et al. 1989; Matthies 1989; Malenka 1991; O'Dell et al. 1991; Matthies and Reymann 1993) suggest that the first $10 \mathrm{hr}$ of long-term synaptic potentiation in the CA1 region can be divided into at least three discrete time-dependent phases on the basis of three independent sets of criteria: (1) the nature of the training protocol-the parameter of tetanization used to induce LTP; (2) selective inhibitors of different second-messenger kinases; and (3) sensitivity to inhibitors of protein synthesis. The first component, STP, is transient and lasts only $\sim 20-30 \mathrm{~min}$. It is induced by a weak tetanus ( $50 \mathrm{~Hz}$ for $0.5 \mathrm{sec}$ ) that is subthreshold for LTP. STP is a result of activation of the $N$-methyl-D-aspartate (NMDA) receptor (Malinow et al. 1989; Bliss and Collingridge 1993). STP is followed by a second component, E-LTP, which is more persistent, lasting 1-3 hr. E-LTP requires a slightly stronger train of stimuli and recruits the action of several kinases, including Cam kinase II, protein kinase $\mathrm{C}$, and one or more tyrosine kinases (Malinow et al. 1989; Malenka 1991; O'Dell et al. 1991). But E-LTP does not require new protein synthesis. Finally, there is L-LTP. This is not induced by a single train but requires repeated trains. In addition to requiring the kinases involved in E-LTP, the late phase requires both PKA and new protein synthesis and persists for $10 \mathrm{hr}$ or more.

Here, we have produced L-LTP by simply repeating the tetanus. This should not be taken to indicate, however, that this is the only way to achieve the late phase. It is likely that by using other manipulations, such as increasing the intensity of the tetanizing volley or increasing the duration of the train, even a single train might produce L-LTP. We would primarily emphasize that repeated tetani are a simple way of dissecting L-LTP from E-LTP.

Thus, our data confirm the general conclusion that has emerged from studies of invertebrates such as Aplysia and Hermissenda (Frost et al. 1985; Montarolo et al. 1986; Dale et al. 1987; Castellucci et al. 1989), that a single training trial tends to induce short-term synaptic changes (lasting minutes to 1 or $2 \mathrm{hr}$ ) that do not require new protein synthesis. In contrast, repeated training trials recruit a more persistent, protein synthesis-dependent phase. However, the recruitment of PKA in L-LTP differs from that in Aplysia in two aspects: (1) PKA is not required for the induction of E-LTP in the CA1 region of the hippocampus but is required for short-term facilitation in Aplysia; and (2) L-LTP does not require persistent PKA activity for its long-term form, whereas the first $10 \mathrm{hr}$ of long-term facilitation in Aplysia requires persistent activity of PKA (Bergold et al. 1990).

Finally, our data provide two additional insights into the mechanisms of LTP. First, the data indicate that LTP is graded, supporting the finding of Hanse and Gustafsson (1992). Although E-LTP lasts longer than STP and is blocked by Cam kinase II inhibitor, it lasts $<3 \mathrm{hr}$. Second, as a corollary, our data suggest that the nature of the early phase of LTP is highly determined by the precise protocol used. With single trains the early phase only reflects the PKA-independent component. With multiple trains a new PKA evident component emerges that is not only present early but grows with time.

Our results also suggest that different kinases are recruited at different thresholds. Cam kinase II and other kinases required for E-LTP seem to be activated by modest tetanization, which induces LTP lasting at least for $1 \mathrm{hr}$. In contrast, the activation of PKA and of L-LTP requires a relatively stronger tetanization. The different effects of the PKA inhibitor on LTP induced by different amounts of tetanization is consistent with our previous assay of cAMP, which showed that significant increases in cAMP level can be obtained after three trains of tetanization but not after one train (Frey et al. 1993).

Does PKA produce its effect on LTP through a pre- or a postsynaptic mechanism? The finding that PKA agonists increase sensitivity of the postsynaptic AMPA receptor in hippocampal neuron culture (Greengard et al. 1991; Wang et al. 1991) suggests a postsynaptic role. In contrast, the ability of the PKA cascade to enhance evoked and spontaneous release of neurotransmitter from Schaffer/commissural terminals suggests that it could also have an additional presynaptic role (Chavez-Noriega and Stevens 1994). Because both the pre- and postsynaptic changes induced by PKA agonist occur rapidly, we think it likely that both loci are recruited by cAMP and PKA for the early component of LTP. The requirement of protein synthesis, however, suggests that a postsynaptic mechanism contrib-

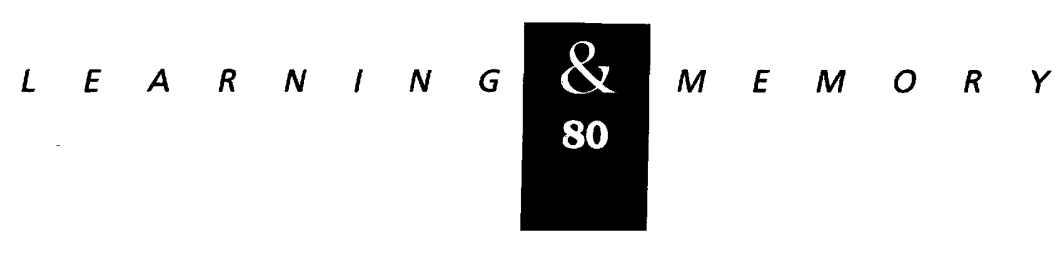


utes to the late and long-lasting component of LTP, perhaps by means of an enduring increase in the sensitivity of the postsynaptic AMPA receptor glutamate (Davies et al. 1989).

\section{Acknowledgments}

E.R.K. is a Senior Investigator at the Howard Hughes Medical Institute. This research is also supported by grants from the National Institute of Mental Health and the DANA Foundation Consortium on Memory and Aging.

The publication costs of this article were defrayed in part by payment of page charges. This article must therefore be hereby marked "advertisement" in accordance with 18 USC section 1734 solely to indicate this fact.

\section{References}

Bergold, P.J., J.D. Sweatt, I. Winicov, K.R. Weiss, E.R. Kandel, and J.H. Schwartz. 1990. Protein synthesis during acquisition of long-term facilitation is needed for the persistent loss of regulatory subunits of the Aplysia cAMP-dependent protein kinase. Proc. Natl. Acad. Sci. 87: 3788-3791.

Bliss, T.V.P. and G.C. Collingridge. 1993. A synaptic model of memory: Long-term potentiation in the hippocampus. Nature 361: 31-39.

Cabell, L. and G Audesirk. 1993. Effects of selective inhibition of protein kinase with cyclic AMP-dependent protein kinase and $\mathrm{Ca}^{2+}$-calmodulin-dependent protein kinase on neurite development in cultured rat hippocampal neurons. Int. Dev. Neurosci. 11(3): 357-368.

Castellucci, V.F., H. Blumenfeld, P. Goelet, and E.R. Kandel. 1989. Inhibitor of protein synthesis blocks long-term behavioral sensitization in the isolated gill-withdrawal reflex of Aplysia. J. Neurobiol. 20: 1-9.

Chavez-Noriega, L.E. and C.F. Stevens. 1992. Modulation of synaptic efficacy in field CA1 of the rat hippocampus by forskolin. Brain Res. 574: 85-92.

Chavez-Noriega, L.E. and C.F. Stevens. 1994. Increased transmitter release at excitatory synapses produced by direct activation of adenylate cyclase in rat hippocampal slices. I. Neurosci. 14: 310-317.

Chetkovich, D.M., R. Gray, D. Johnston, and J.D. Sweatt. 1991. N-methy-D-aspartate receptor activation increase cAMP levels and voltage-gated $\mathrm{Ca}^{2+}$ channel activity in area CA1 of hippocampus. Proc. Natl. Acad. Sci. 88: 6467-6471.

Dale, N., E.R. Kandel, and S. Schacher. 1987. Serotonin produces long-term changes in the excitability of Aplysia sensory neurons in culture that depend on new protein synthesis. J. Neurosci. 7: 2232-2238.

Davies, S.N., R.A. Lester, K.G. Reymann, and G.C. Collingridge. 1989. Temporally distinct pre- and postsynaptic mechanisms maintain long-term potentiation. Nature 338: $500-503$.

Frey, U., Y.-Y. Huang, and E.R. Kandel. 1993. Effects of cAMP stimulate a late stage of LTP in hippocampal CA1 neurons. Science 260: 1661-1664.

Frost, W.N., V.F. Castellucci, R.D. Hawkins, and E.R. Kandel. 1985. Monosynaptic connections made by the sensory neurons of the gill- and siphon-withdrawal reflex in Aplysia participate in the storage of long-term memory for sensitization. Proc. Natl. Acad. Sci. 82: 8266-8269.

Greengard, P., J. Jen, A.C. Nairn, and C.F. Stevens. 1991. Enhancement of the glutamate response by cAMP-dependent protein kinase in hippocampal neurons. Science 253: 1135-1138.

Hanse, E. and B. Gustafsson. 1992. Postsynaptic, but not presynaptic, activity controls the early time course of long-term potentiation in the dentate gyrus. J. Neurosci. 12: $3226-3240$.

Hashimoto, Y., T. Nakayama, T. Teramoto, T. Watanabe, M. Kinashita, and K. Tsukamoto. 1993. Potent and preferential inhibition of $\mathrm{Ca}^{2+} /$ calmodulin-dependent protein kinase II by K252a and its derivate KT5926. Biochem. Biophys. Res. Commun. 181: 423-429.

Malenka, R.C. 1991. Postsynaptic factors control the duration of synaptic enhancement in area CA1 of the hippocampus. Neuron 6: 53-60.

Malenka, R.C. and R.A. Nicoll. 1990. Intracellular signals and LTP. Sem. Neurosci. 2: 335-343.

Malenka, R.C., J.A. Kauer, D.J. Perkel, M.D. Mauk, P.T. Kelly, R.A. Nicoll, and M.N. Waxham. 1989. An essential role for postsynaptic calmodulin and protein kinase activity in long-term potentiation. Nature 340: 554-557.

Malinow, R., H. Schulman, and R. Tsien. 1989. Inhibition of postsynaptic PKC or CAMKII blocks induction but not expression of LTP. Science 245: 862-866.

Matthies, H. 1989. In search of cellular mechanisms of memory. Prog. Neurobiol. 32: 277-349.

Matthies, H. and K.G. Reymann. 1993. Protein kinase A inhibitors prevent the maintenance of hippocampal long-term potentiation. NeuroReport 4: 712-714.

Montarolo, P.G., P. Goelet, V.F. Castellucci, J. Morgan, and E.R. Kandel. 1986. A critical period for macromolecular synthesis in long-term heterosynaptic facilitation in Aplysia. Science 234: 1249-1254.

O'Dell, T.J., E.R. Kandel, and S.G.N. Grant. 1991. Long-term potentiation in the hippocampus is blocked by tyrosine kinase inhibitors. Nature 353: $558-560$.

Otani, S., M.P. Roisin-Lallemand, and Y. Ben-Ari. 1992. Enhancement of extracellular protein concentrations during

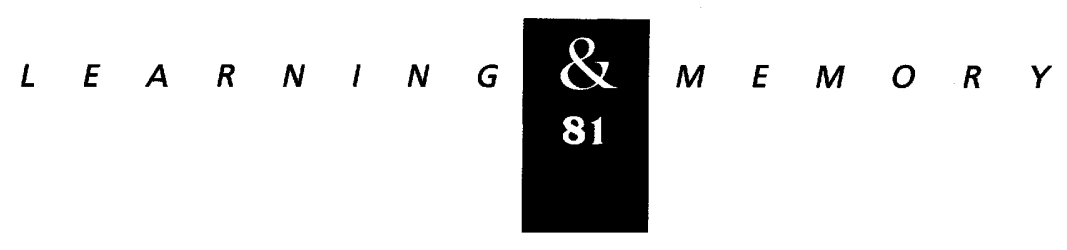


Downloaded from Karnmem .cshlp.org on April 26, 2023 - Published by Cold Spring Harbor Laboratory Press

long-term potentiation in the rat hippocampal slice.

Neuroscience 47: 265-272.

Squire, L.R. 1992. Memory and the hippocampus; A

synthesis from findings with rat, monkeys, and humans.

Psychol. Rev. 99: 195-231.

Stephen, J.M., T.G. Smart, C.D. Blackstone, and R.L.

Huganir. 1992. Functional modulation of $\mathrm{GABA}_{\mathrm{A}}$ receptor by

cAMP-dependent protein phosphorylation. Science

257: 661-665.

Wang, L.-Y., M.W. Salter, and J.F. MacDonald. 1991.

Regulation of kainate receptors by CAMP-dependent protein

kinase and phosphatases. Science 253: 1132-1135.

Received March 17, 1994; accepted in revised form April 21 , 1994. 


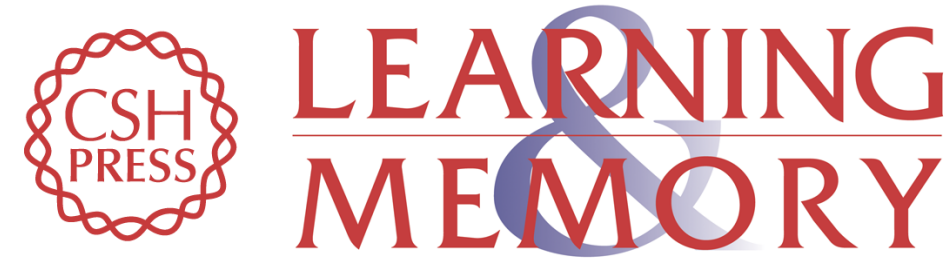

\title{
Recruitment of long-lasting and protein kinase A-dependent long-term potentiation in the CA1 region of hippocampus requires repeated tetanization.
}

\author{
Y Y Huang and E R Kandel \\ Learn. Mem. 1994, 1: \\ Access the most recent version at doi:10.1101//m.1.1.74
}

$\begin{array}{ll}\text { References } & \text { This article cites } 26 \text { articles, } 12 \text { of which can be accessed free at: } \\ \text { http://learnmem.cshlp.org/content/1/1/74.full.html\#ref-list-1 }\end{array}$

\section{License}

Email Alerting Receive free email alerts when new articles cite this article - sign up in the box at Service the top right corner of the article or click here. 